\title{
Dust, noise and chemical solvents exposure of workers in the wooden furniture industry in South East Asia.
}

\begin{abstract}
A study was carried out to evaluate the dust, noise and chemical solvents exposure among workers in the wooden furniture industry in the South East Asian region comprising Malaysia, Thailand, Indonesia and Vietnam. A total of 30 factories were selected from each country for the study. Air quality samples at the machining and sanding workstations were measured using the micro-orifice uniform deposit impactor (MOUDI), which separated the particles into different sizes. The results showed that the average dust concentration in the machining section was lower than that in the sanding section, but total inhalable dust particles of less than $10 \mu \mathrm{m}$ in diameter, was less than $25 \%$ by weight. Portable noise-level measurements showed that the rough-milling operations recorded the highest noise-level in the furniture factories in the region. Personal dosimeter measurement results show that $43 \%$ of the workers were exposed to noise-levels higher than the permissible limit, with $34.7 \%$ of the workers suffered from hearing handicap. The study also found that the current exposure levels for both chemical solvents and formaldehyde in the wooden furniture industry in the countries within the South East Asian region were higher than the Permissible Exposure Levels (PEL). Therefore, it was apparent that despite the existent of a comparable Occupational Health and Safety regulations in the region, its implementation and enforcement within the wooden furniture industry must be improved to ensure the workers safety and health.
\end{abstract}

Keyword: Safety and health; Workers; Wooden furniture; Permissible exposure limit. 